\title{
In-situ Grafting Hydrophilic Polymeric Layer for Stable Drag Reduction
}

\begin{tabular}{|c|l|}
\hline $\begin{array}{c}\text { Complete List of } \\
\text { Authors }\end{array}$ & $\begin{array}{l}\text { Chaoguo Tian; } \\
\text { Xingwei Wang; } \\
\text { Wufang Yang; } \\
\text { Haibao Hu; } \\
\text { Xiaowei Pei; } \\
\text { Feng Zhou; }\end{array}$ \\
\hline The number of pages & $\begin{array}{l}\text { Fig.S1. Static displacement of steel sphere at the same time } \\
\text { interval during freely fall in cylindrical tank. } \\
\text { Fig.S2. The displacement - time curve of the sphere falling } \\
\text { freely in a cylindrical tank 2 m high. } \\
\text { Fig.S3. The velocity-time curve fitting process of unmodified } \\
\text { spheres and spheres modified by hydrogel layers with } \\
\text { different thickness. } \\
\text { Fig.S4. Comparison curve of velocity time between 30mm } \\
\text { hydrogel layer steel sphere and blank steel sphere. }\end{array}$ \\
\hline Figures & \multicolumn{2}{|c}{ N/A } \\
\hline Tables & \multicolumn{2}{|c|}{} \\
\hline
\end{tabular}




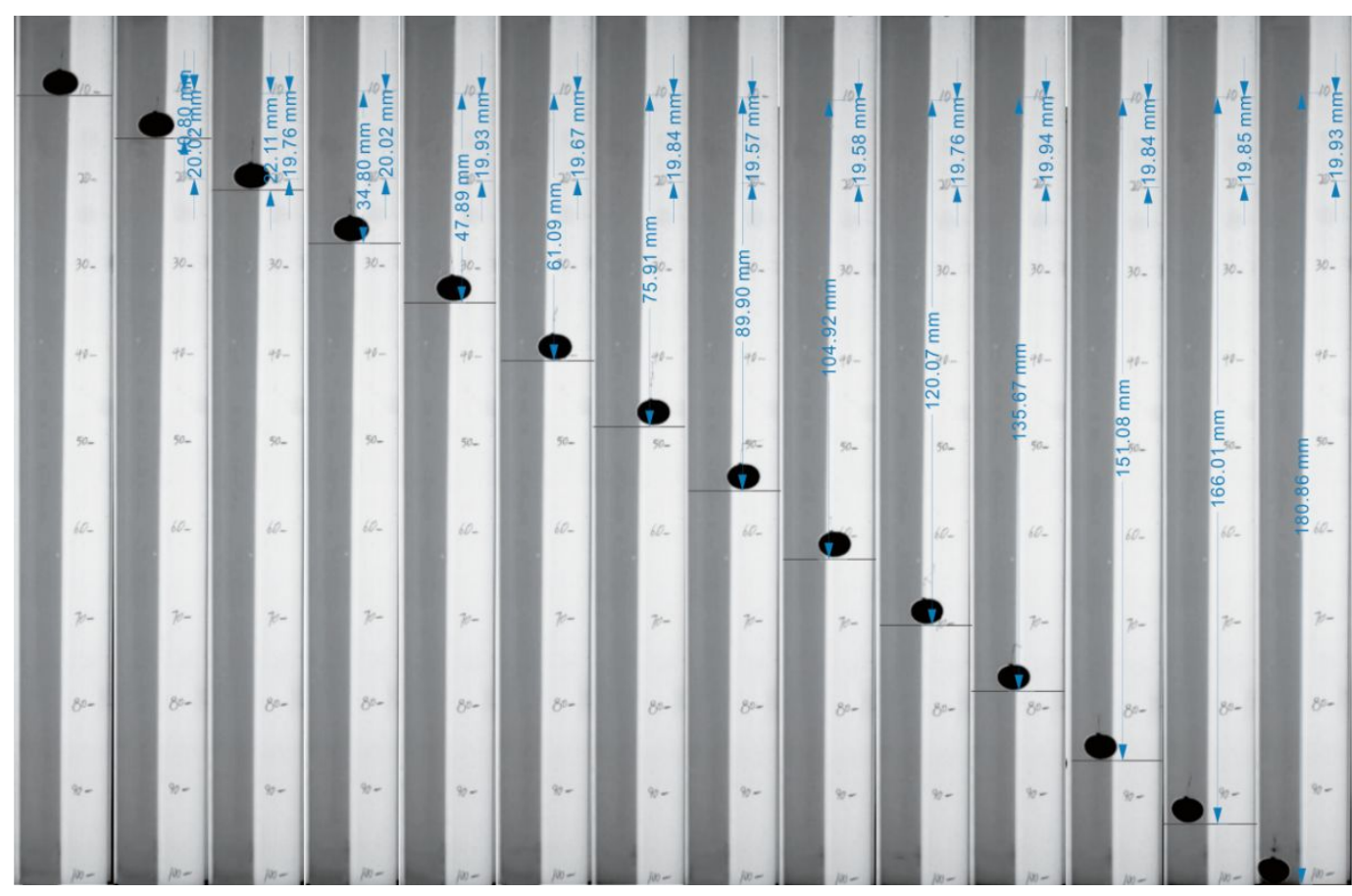

Fig. S1 Static displacement of steel sphere at the same time interval during freely fall in cylindrical tank. The experimental process of hydrogel layer steel spheres and polished steel spheres was recorded in the same way. 

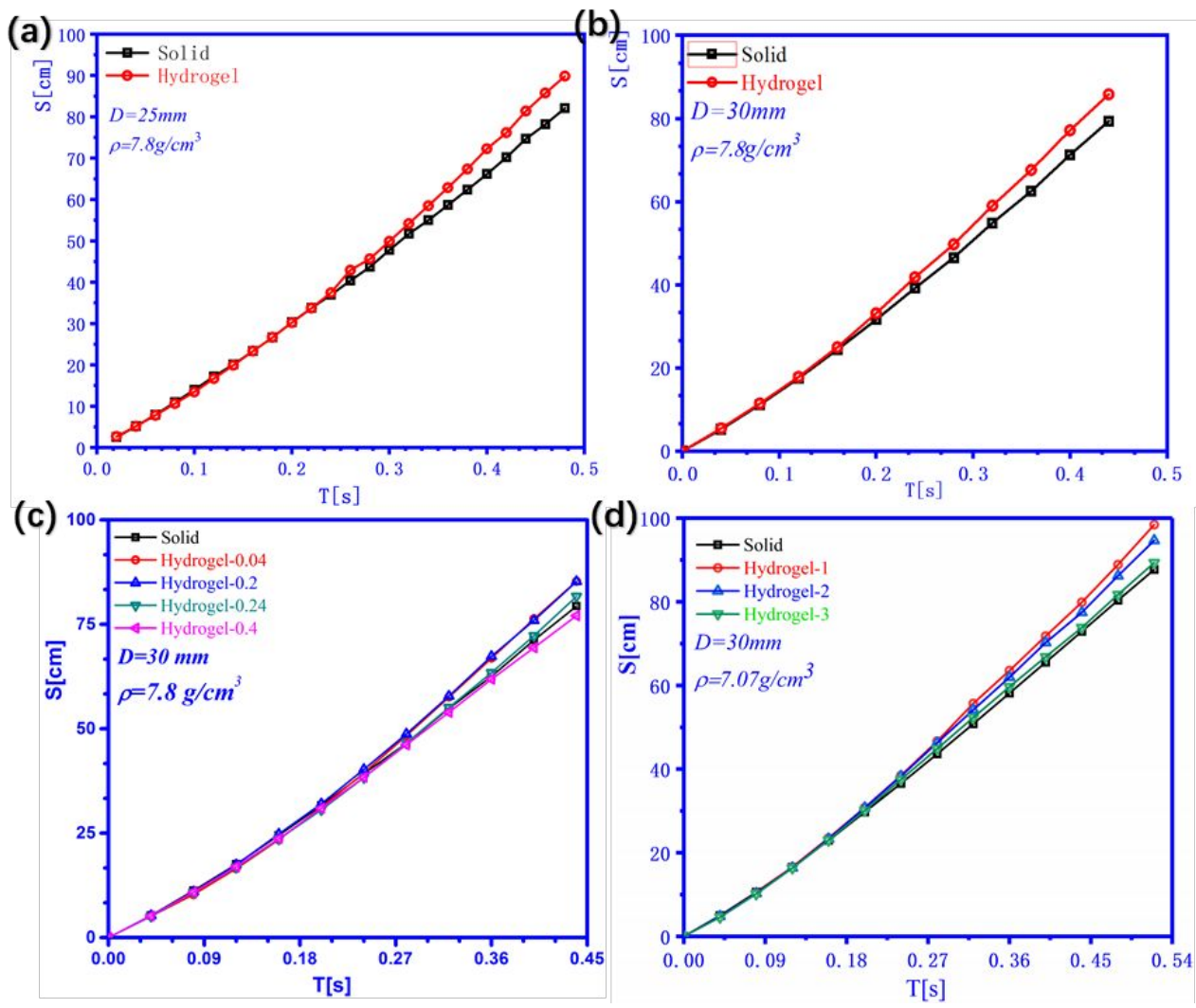

Fig. S2 The displacement - time curve of the sphere falling freely in a cylindrical tank $2 \mathrm{~m}$ high. (a) $25 \mathrm{~mm}$, (b) $30 \mathrm{~mm}$ : The displacement time comparison curve of unmodified steel sphere and superhydrophilic gel layer steel sphere; (c) Time curve of steel sphere displacement with different crosslinking degree, (d)Time curve of steel sphere displacement with different thickness. 

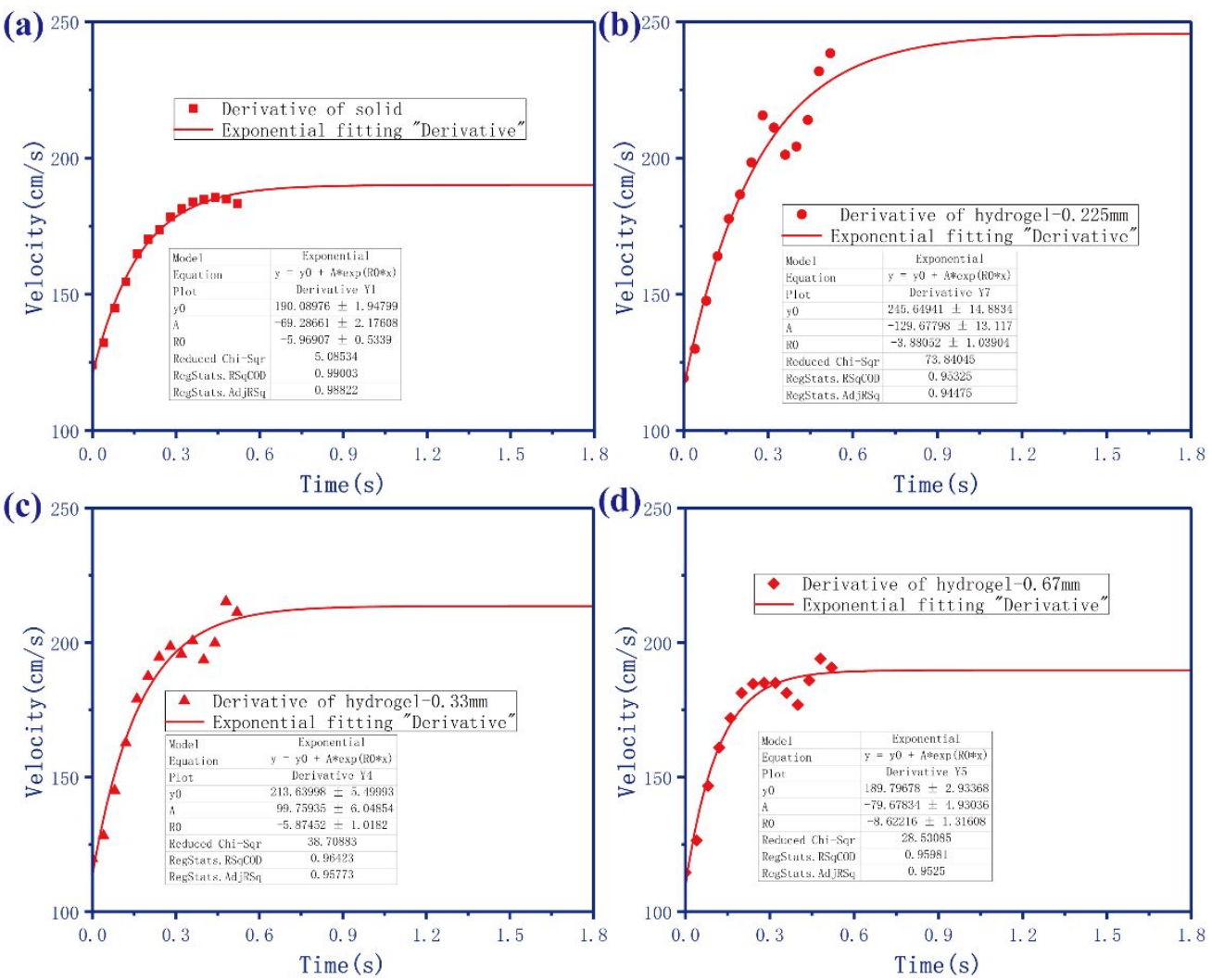

Fig. S3 The velocity-time curve fitting process of unmodified spheres and spheres modified by hydrogel layers with different thickness. (a) is the process of fitting the velocity - time curve of the unmodified sphere. (b), (c) and (d) are respectively the velocity-time curve fitting process of the sphere modified by hydrogel layer with thickness of $0.225 \mathrm{~mm}, 0.33 \mathrm{~mm}$ and $0.67 \mathrm{~mm}$. 


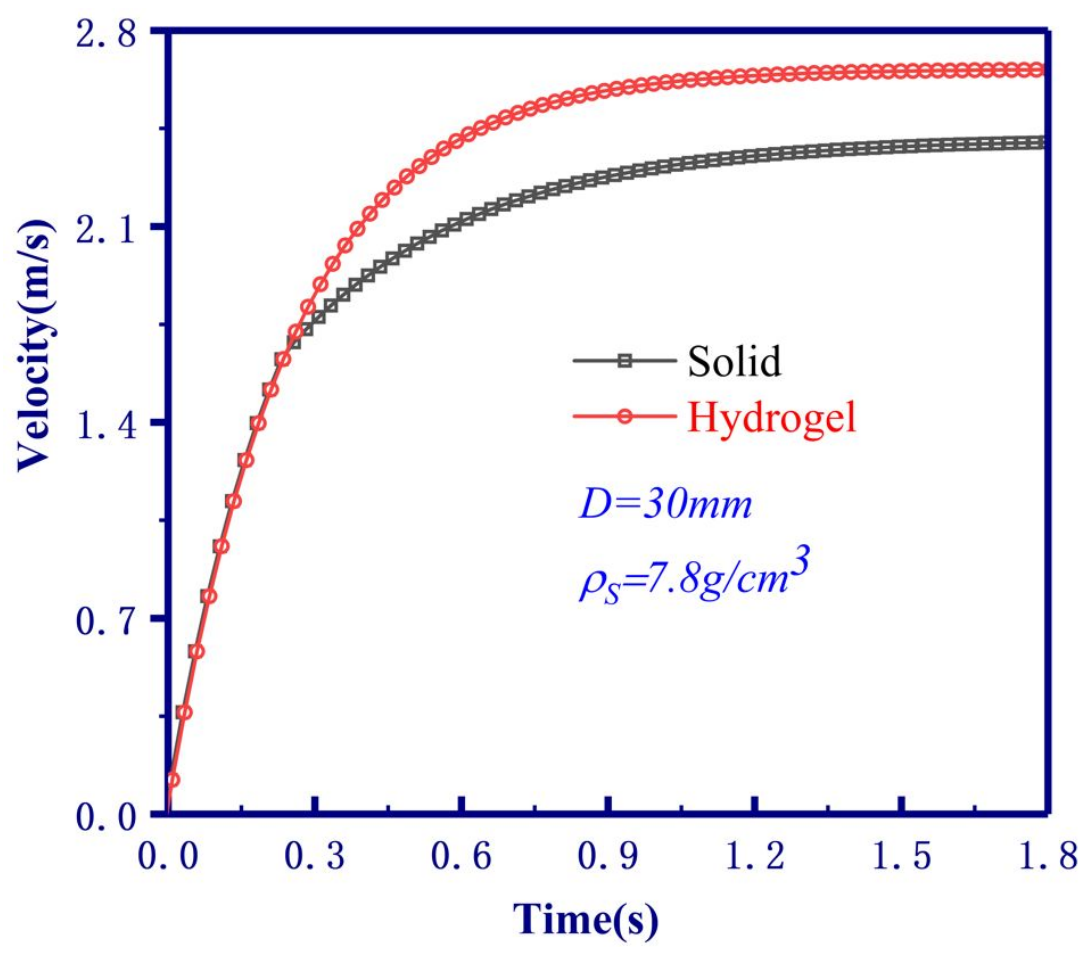

Fig. S4 Comparison curve of velocity time between 30mm hydrogel layer steel sphere and blank steel sphere. The curve is obtained by fitting the displacement time curve. 